\title{
The Forming Conditions and Cultural Consensus of the Silk Road Spirit Core Value
}

\author{
Lu-qing YAO \\ Marxist College, Shanghai Normal University, Shanghai, China
}

Keywords: The Silk Road Spirit; Core Value; Cultural Consensus.

\begin{abstract}
For thousands of years, the long-term friendly exchanges between the countries along the Silk Road have gradually formed a cultural consensus. The natural conditions promote the exchange of different cultures, the cooperation of different regional economies, and the Silk Road Spirit "peace and cooperation, openness and inclusiveness, mutual learning and mutual benefit". Mutual respect and mutually-beneficial cooperation among countries are the important mechanisms for forming the spirit of the Silk Road; openness and cooperation are the preconditions and principles of the Silk Road Spirit; people-to-people and cultural exchanges, and mutual learning among the peoples of the relevant countries are the cultural basis of the spirit of the Silk Road; the peoples of the relevant countries to understand, trust and respect each other and live in harmony are the ideals and goals of the Silk Road Spirit. It is the core value that has made the spirit of the "Silk Road" rejuvenate in the 21 st century and has become the ideological foundation of the common spiritual homeland in the "Belt and Road".
\end{abstract}

\section{Introduction}

The Chinese government has drafted and published "the Vision and Actions on Jointly Building Silk Road Economic Belt and 21st-Century Maritime Silk Road" which indicated that the spirit of the Silk Road - "peace and cooperation, openness and inclusiveness, mutual learning and mutual benefit" - has advanced the progress of human civilization for thousands of years. The spirit of the Silk Road is an important link for the prosperity and development of relevant countries, a symbol of exchanges and cooperation between the east and the west, and a historical and cultural heritage shared by all countries in the world. Why is "peace and cooperation, openness and inclusiveness, mutual learning and mutual benefit" the core value of the spirit of the Silk Road? How does this core value come into being, and how does the Chinese culture demonstrate its value and strength? Historical and academic research on these issues is beneficial to the initiative of the "Belt and Road" in the new era.

\section{The Forming Conditions of the Silk Road Spirit Core Value}

\subsection{Natural and history conditions}

More than 2,000 years ago, the people in Eurasia explored and opened up several routes of trade and cultural exchanges that linked the major civilizations of Asia, Europe and Africa, collectively called the Silk Road by later generations. The traditional "Silk Road" refers to the route from the mainland of China to the Eurasian continent, divided into the Land Silk Road and the Maritime Silk Road. The Land Silk Road can be divided into three categories: the first is the Oasis Silk Road (also known as the Desert Silk Road), referring to the road from the Hexi Corridor to the oasis in the deserts of Central Asia. It originates from North China, passes through the Hexi area, the Tarim Basin, goes to West Asia, Asia Minor, etc. The second is the Prairie Silk Road, referring to the traffic road that runs across the northern grassland of Eurasia, from the north of the Yellow River to the Mongolian Plateau, and through the Siberian steppe to the European region of the Mediterranean North. The third is the South Silk Road, referring to the route beyond Sichuan, Guizhou, Yunnan, Tibet and Guangxi to India and Southeast Asia. The Maritime Silk Road stems from the southeast coast of China, and passes through the South China Sea, the Indian Ocean, the 
Persian Gulf, Far East Africa and Europe, becoming an important route for the communication of global civilization.

The South Silk Road was formed more than two thousand years ago in the Han Dynasty. Beginning with the circulation of private businesses, Silk Road originated in Chengdu, and it is the hometown of Chinese silk and tea, the cradle of salt and iron, and the first city in southwestern China. According to the official tradition, the Silk Road started from the time of Emperor Wu of the Western Han Dynasty, Zhang Qian is an imperial envoy to the world outside of China. This represents the "official contacts" between ancient China and another country. Shipbuilding technology has made great progress in Tang Dynasty. The sailors have also mastered the seamanship and trade has established fixed routes and ports. Yangzhou, Guangzhou, and Mingzhou (now Ningbo) have developed into important coastal economic and commercial centers, and the maritime Silk Road has formed. Yuan Dynasty, Genghis Khan and its descendants swept Eurasia along the Silk Road route, linking not only the southern and northern roads of the Prairie Silk Road, but also linking the Oasis Silk Road of the Hexi Corridor, and the South Silk Road to South Asia, as well as the Maritime Silk Road which link he southeastern coast of China with the Mediterranean Sea and on the east coast of Africa. The economic and cultural exchanges between East and West have entered the most prosperous stage of development. After the modern times, due to the development of the Western industrial revolution and colonial aggression, the countries along the Silk Road suffered different degrees of damage. The shocks made a positive and effective response and began to move from prosperity to recession.

For more than 2,000 years, the Silk Road has basically not changed its way. This is not because people like to follow the footsteps of their predecessors, but they are limited by the physical and geographical environment. For example, around the Taklimakan Desert, there are large and small oases, which are maintained by the rivers formed by the glaciers melting snow. In the ancient western regions, an oasis was often a small country. If the river diverts or dries up, quicksand gradually covers and the country will become a ruin. The development of the Silk Road has brought prosperity to the countries in the western region along the route. This has enabled the exchange and cooperation of countries along the route for thousands of years to continue without interruption.

\subsection{Cultural conditions}

Over the years, the cultural exchanges between the countries along the Silk Road became deeper and deeper. Their cultural "mutual learning" has made the culture of all countries along the Silk Road learn and progress together, which provide the basis to the development of modern the "Belt and Road". For example, India's phonetics has played an important role in the development of China's Anti-cut. In addition, classical works such as Journey to the West, The Romance of the Three Kingdoms, and the Water Margin are widely circulated in East Asia and Southeast Asia. Moreover, the four great inventions of ancient China were also transferred to Europe through Central Asia and Western Asia through these land and sea routes. The traditional customs of western countries and various arts such as European music and dance, painting, sculpture were gradually received by the eastern countries. It promoted mutual exchanges and understanding among countries along the Silk Road. "Travels of Marco Polo" mentions that "A black stone was found throughout the entire Khitan Province. It was dug from mines and extended underground. Once ignited, it had the same effect as charcoal. And its flame is bigger and more prosperous than charcoal." Marco Polo said that as a fuel consumption "wood resources are difficult to meet supply, but these black stones are inexhaustible, and the price is very low." [1] Marco Polo then brought the knowledge of using coal back to Europe, making China's coal culture spread.

\subsection{Economic conditions}

In ancient China, through the Silk Road, economic and trade exchanges with other countries in the world were frequent. While silk, tea, and porcelain were sent to various countries in the western region. At the same time, coral, jade, ivory, amber, and glass from West Asia and Central Asia also flowed into China. Besides, Chinese and foreign businessmen also carry out transit trade of rare items and luxury goods, such as gold and silver products, precious stones, pearls, carpets, good 
horses, and medicinal herbs. China's water irrigation technology was passed down from the Han Dynasty to the West. Similarly, some foreign products and exotic animals have also been introduced into China through the Silk Road to attain economic cooperation. Zhang Qian is an imperial envoy to the world outside of China, and brought back some species, the grapes and Cao He are the most well-known ones, as well as Ann Pomegranate and Yellow Blue. In addition, many crops with the word "Hu" appeared at the time, such as flax, walnuts, beans, pepper, courgettes, garlic, all of which were introduced from the western regions. These titles have continued until today. There are also many spices coming from the western regions, such as Arabian frankincense, Somalia aloe vera, Suhexiang, benzoin, rosemary in North Africa, purple plant in East Africa and so on. Many of these spices were brought into China using finished products, which nourished the lives of the Chinese people. Many spices were used as drugs at that time. At the same time, a number of crops have been passed down to the Central Plains, such as corn, rice, peanuts, sunflowers, potatoes, and tomatoes, which enriching the variety of crops and affecting the diet structure of the Chinese nation. Some rare animals have also been introduced to the Central Plains with tribute, which has greatly affected our life today, and has brought a form of economic exchanges between the countries along the Silk Road.

The cultural exchanges and economic cooperation between the countries along the "Belt and Road" have enabled the cultures of the countries consciously and unconsciously entering this economic and cultural exchange circle, and at the same time becoming the basis for economic exchange and benefit sharing. In addition, the Silk Road Spirit "peace and cooperation, openness and inclusiveness, mutual learning and mutual benefit" has been formed. It has become an important link to promote the progress of human civilization and promote the prosperity and development of all ethnic groups along the Silk Road and a symbol of exchanges and cooperation between the East and West.

\section{The Cultural Identity of the Silk Road Spirit Core Value}

\subsection{Mutual respect, work together}

Archaeologists found a large number of simple books in the Xuanquan Posthouse site of the Han Dynasty near the sweet water well in Dunhuang. These simple documents contain detailed records of the number, identity, tasks, whereabouts, etc., even foreign guests, as well as the ethnicity of the population here. These documents show Zhang Xuan's Xuan Xuan County, which is the name of ancient Chinese in the Han Dynasty. According to records, there was a fierce battle between the ancient Romans and the Persian Empire. After the defeat of Rome, a unit of the Roman legion did not know where it was. In recent years, many scholars have suspected that this Roman army may have flown to the Lixuan County of Yongchang City, Gansu Province today, which is the Roman city of the Han Dynasty. Whatever this legend is true or not, in the history, the Hexi Corridor is indeed a crossroads of ethnic migration and a melting pot of ethnic blending. The large stage of the ancient national turn of the show, many national and national political powers have appeared here. In fact, in many nations, their culture merged different grassland culture, such as Turkic, Tuyu, Tubo, Yi and Mongolia, which have been active in the Hexi Corridor since the beginning of the Christian era. The ancient Silk Road is a confirmation to the exchanges, contacts and integrations between the countries along the ancient times.

Different ethnic groups have their own cultural advantages, and the advantages of different cultures complement each other to attract and supplement each other. In a certain sense, this has become a division of labor. On the other hand, different countries have an expectation to gain benefits from interactions with other countries, thus forming a close relationship between the countries on the Silk Road. The cultural wealth created by the people of all countries is an important medium for this connection. Mutual respect, work together, these concepts have become the principle of value that is shared by different countries in the long-term exchanges, contacts and integrations. On the basis of these concepts, a social mechanism of mutual respect and work together has been formed. Under the support of this mechanism, the Silk Road has been prosperous 
for thousands of years.

\subsection{Openness and inclusiveness, negotiation and collaboration}

There is undoubtedly a competition and a game between the countries along the Silk Road in economic exchanges. However, the openness and mutual benefit between them in the common interests is the essence of competition and game. In the long-term exchanges and communications, different countries always overcome the interference in communication on this land to maintain state exchanges, and to maintain the smooth flow of the Silk Road. Western businessmen came to China to do business, with the largest number of Persian and Central Asian. The Zhaowu Nine States, located in the Amu Darya and the Syr Darya River, are the Kangju and Dawan of the Han Dynasty. During the Tang Dynasty, the residents of the Nine Kingdoms were relocated from the Hexi Corridor in the previous generation. Their surnames were mostly Kang, An, Shi, Mi, Cao and He. China is their homeland, although they live in Central Asia, they still maintain the Chinese surname, which means they have not forgotten the ancestor. It is recorded by the Tang Dynasty Shazhou Tujing: in the Zhenguan period, the Samarkand leader Kang Yandian came to Dunhuang, and many people in the family followed and settled down. Then gradually the barbarians moved here to form a town called stone [2]. On the Silk Road main line, there are many units, such as military, town, guardian, scorpion and other military defense units, also many pavilions set up to entertain merchants. It is the openness and inclusiveness between the various countries on the ancient Silk Road that can provide mutually beneficial and convenient conditions for the merchants on the Silk Road, and make the countries along the line pursue negotiation and collaboration.

In fact, different countries in the long-term exchanges, contacts and integrations, which constantly coordinate their relations and expand cooperation. Non-governmental exchanges have promoted economic and cultural communication among people of all countries and reduced competition and conflicts in economic exchanges. However, its far-reaching significance lies in the fact that the people's exchanges, contacts and integrations have made the relationship between the people of the world more refined and more human. The relationship of Regional nations became organic, complementary, flesh-and-blood relationships. The interaction of various countries on this land from the shallow interactive system to the organizational connection, and finally to the social system, which expresses the common needs and common interests of different countries, thus making this system to the premise and principles of the Silk road spirit.

\subsection{People-to-people exchanges and mutual learning among civilizations}

Cultural communication and exchanges enable countries along the route to make their economic development strategies and organically connect to find common interests by friendly dialogue and consultation. In addition, they formulate plans and measures to promote regional cooperation. The communication of culture can connect the people of different countries and different nationalities, and lay a solid foundation of public opinion and social foundation for regional cooperation and common maintenance of regional harmony and stability. The reason why culture exists in communication is first of all the diversity and difference of culture, which means that different cultures have different characteristics. [3] For example, coins are the most direct physical evidence for the sale of goods. Various kinds of ancient coins were unearthed in Hetian. The Han dynasty two-body money is also called Hetian Ma Qian. It is a copper coin made by the ancient Greek casting method. It has Chinese characters on one side and Lu Wen on the other side, so it is called Han dynasty two-body money. Although there are still many problems with the Han Shu two-body money, experts need to study and solve them. However, it is undoubtedly a historical testimony of the activities of the various nationalities in the East and the West.

The Western region culture on the Silk Road of ancient oasis is a witness of the humanities exchanges and civilizations of all countries along the line. It combines the four major cultures of mankind: Chinese culture, Indian culture, Arab Islamic culture and ancient Greece culture. Western culture brings together the wisdom of many peoples of the world and the essence of the four major cultural systems, forming a highly inclusive cultural system. In the cultural exchange of the Silk Road, the Chinese nation has provided tremendous cultural contributions to countries along the 
route. At the same time, the Chinese nation has also taken a variety of cultural factors from the countries along the route, enriching its material and spiritual culture. Mutual understanding with civilization is the cultural basis for the formation of the "Silk Road" spirit.

\subsection{Peaceful coexistence, trust and respect each other}

The largest treasure house of Buddhist art on the ancient Silk Road, one is the Kizil Thousand Buddha Cave and the other is Mo Kao Grotto at Dunhuang. The Kizil Thousand-Buddha Cave is located in the northwest of Kuqa in Xinjiang, the ancient Kucha country and the Tang'an government, which was the political, economic, military and cultural center of the Western Region that naturally became the center of Buddhism. Kizil is best known for his Buddhist murals, which are painted in the diamonds on the wall. One of the Bodhisattva burning an arm leading the way for visitors is particularly eye-catching. On the dark night of the picture, a bodhisattva is exposed to the upper body, wearing a streamer holding a burning arm, guiding the lost caravan. Holding the camel's porters, pay tribute to the Buddha who gave up their body. This painting not only reflects the Buddhist scriptures, but also expresses the wishes of the silk merchants. The Dunhuang Mo Gao Grotto are larger in scale and have a longer history and richer content. The Mo Gao Grotto were built from the 4th to the 14th centuries and have retained 492 caves from 10 dynasties for more than 1,000 years. The most numerous caves of the Tang Dynasty left many beautiful sculptures and murals, which reflected the thoughts of the karma of people who endured suffering at that time. In the Tang Dynasty, the focus began to depict the ideal "human paradise." The background is an idealized sandbar native. People have fantasized that Dunhuang had a good weather and lush crops, which also reflected the prosperity of Dunhuang in the Tang Dynasty. The imprints left over from history prove that people along the ancient Silk Road have always longed for peace, mutual trust, mutual respect, and a prosperous life. This ideal and goal provide value ideals and goals for the development of the "One Belt, One Road" strategy today.

\section{Main Conclusion}

During the long historical development of the Silk Road, the cultural consensus satisfies the needs of exchanges, contacts and integrations between countries along the Silk Road on both the spiritual and practical levels, thus contributing to the development of the Silk Road. With the gradual expansion of the exchanges between countries along the Silk Road, the cultural appeals of different countries have become more and more obvious. The simple relationship has further expanded into a deeper cultural and psychological connection, and the specific national sentiment has become more integrated. The links between countries within the scope have formed a common sentiment with the characteristics of multiculturalism, forming the core value of "peace and cooperation, openness and inclusiveness, mutual learning and mutual benefit" in the spirit of the Silk Road.

Peace and cooperation, political and military cooperation between countries along the line are greater than war. President Xi Jinping mentioned that "China will adhere to the path of peaceful development and will also promote the common development of all countries." [4] On the basis of the "kindness ethics" principle of "treat others as ourselves", Chinese culture has formed a relatively equal view of the nation. During the Tang Dynasty, Han people, Barbarian, Western monks, and big food guests crossed the Silk Road and coexisted in harmony and symbiosis of multiple civilizations, outlining a multi-ethnic friendly exchange and sharing of peace and cooperation along the line. The Silk Road in history is the road to peace, the road to cooperation and the road to friendship. On this important passage of the Eurasian continent, the traces of the friendly exchanges between the various countries along the ancient Silk Road have also become a witness history for "Belt and Road" today.

Openness and inclusiveness, diplomacy is more open than closure, and tolerance is greater than exclusion. Since the formation of the Silk Road, the countries along the line have maintained friendly cooperation in the spirit of openness and inclusiveness. The ancient Eurasian continent linked the two civilizations of the East and the West. This is closely linked to the Silk Road and 
became the center of world civilization. The Ottoman Turkish Empire rose, then cutting off the Oasis Silk Road. It did not close the exchanges between the various countries along the line, but instead made the Silk Road go to the ocean. "Belt and Road" development strategy is the urgent need for open communication among the various countries along the Silk Road. People of all nationalities comply with the "five links" of policy, trade, transportation, currency and people's heart to connect peace, growth, reform and civilization, which has enabled Eurasia to re-establish the center of human civilization and achieve lasting peace and common prosperity for mankind.

Mutual learning, cultural exchanges and progress are greater than cultural mutual exclusion. The diversity of civilization is the driving force for the development and progress of human culture. The opening of the Silk Road communicated the connection between the East and the West, and the continuous spread of Chinese civilization to the West, which greatly influenced the Western world and greatly promoted the process of world civilization. After Zhang Qian paid a friendly visit to the west, China's iron and iron technology was introduced to Central Asia along the Silk Road via Xinjiang. The use of ironware is one of the important indicators of the progress of social productivity development. Chinese medicine was also introduced to the Arabs along with the Silk Road. In the 8th century AD, the diagnosis method of Chinese medicine diagnosis was introduced into the Arab region. From the late 16th century to the early 17th century, Europeans such as Li Ma Dou and Tang Ruowang came to China to translate and introduce the Compendium of Materia Medica into Europe. The integration of Eastern and Western medicine promoted the development of modern medicine.

Mutual benefit and win-win situation are more competitive than differential competition. Luo Nengsheng thought that "The cultural traits of different countries determine the diversity of commodity culture. Because the diverse commodity culture appeal can meet the diversified consumer preferences and spiritual needs of different consumers, thus cultural differences are the important source and foundation for the emergence of international trade." [5] Under the condition of incomplete market competition, the difference of commodities is an important reason for international trade. The unique cultural value of each country's goods will create a strong attraction for foreign consumers, and then generate consumer demand. The reason why ancient Chinese silk, porcelain, and tea have long enjoyed a good reputation in the history of world trade and promoted the development of foreign trade among countries is that these commodities are rich in unique culture and civilization, and they become mutually beneficial in economic and trade along the Silk Road, which is an important cultural reason for a win-win situation.

Today, the "Belt and Road" is an important strategy for China's opening up to the outside world in the new era. The important support of its conception and practice is based on the value recognition generated by the Chinese civilization and the countries along the route for thousands of years of exchanges, contacts and integrations. The culture of a country is accumulated and passed down in the long history of history, and it is constantly evolving along with the changes in the production and life style of the nation. Each country has its own unique culture different from other nations [6]. The recognition of this core value concept has enabled the "Silk Road" spirit to be passed on from generation to generation, and it has given new vitality in the 21 st century, and has become the ideological foundation of the common spiritual homeland in today's "Belt and Road" construction. And this is the value of exploring this topic.

\section{Acknowledgement}

This research was financially supported by the CHINA SCHOLARSHIP COUNCIL.

\section{References}

[1] Marco Polo, 1981, The travels of Marco Polo, Fujian science and technology press, 124-125.

[2] Shazhou Tu Jing. Shanghai: Shanghai gu ji chu ban she, 2002. Print.

[3] Xinjiang Song, 2001, China and foreign civilization, Xinzhi Sanlian bookstore. (In Chinese) 
[4] Information on http://news.qq.com/a/20140516/001966.htm

[5] Nengsheng Luo, Lianying Hong, Cultural Interpretation of International Trade [J], Seeking Truth, 2016, Vol. 11. (in Chinese)

[6] Xingsheng Ma, Reflections on the Compliance Theory of Regional National Economy and Regional National Culture [J], Journal of Central China Normal University, 2010, Vol. 01. 